\title{
An Analytical Assessment of NASA's N+1 Subsonic Fixed Wing Project Noise Goal
}

\author{
Jeffrey J. Berton ${ }^{1}$ and Edmane Envia ${ }^{2}$ \\ NASA Glenn Research Center, Cleveland, Ohio 44135 \\ and \\ Casey L. Burley ${ }^{3}$ \\ NASA Langley Research Center, Hampton, Virginia 23681
}

\begin{abstract}
The Subsonic Fixed Wing Project of NASA's Fundamental Aeronautics Program has adopted a noise reduction goal for new, subsonic, single-aisle, civil aircraft expected to replace current 737 and $\mathbf{A 3 2 0}$ airplanes. These so-called " $\mathrm{N}+1$ " aircraft - designated in NASA vernacular as such since they will follow the current, in-service, " $N$ " airplanes - are hoped to achieve certification noise goal levels of 32 cumulative EPNdB under current Stage 4 noise regulations. A notional, $\mathrm{N}+1$, single-aisle, twinjet transport with ultrahigh bypass ratio turbofan engines is analyzed in this study using NASA software and methods. Several advanced noise-reduction technologies are analytically applied to the propulsion system and airframe. Certification noise levels are predicted and compared with the NASA goal.
\end{abstract}

\section{Nomenclature}

$A F E \quad=$ altitude above field elevation

$E P N L=$ effective perceived noise level

$F A R=$ federal aviation regulations

$I S A=$ international standard atmosphere

$L S W T=$ NASA Glenn Research Center Low Speed Wind Tunnel

$O A S P L=$ overall sound pressure level metric

$P N L \quad=$ perceived noise level metric

$P N L T=$ perceived noise level with tone weighting metric

$S L S \quad=$ sea level static

$U H B=$ ultrahigh bypass

\section{Introduction}

$\mathrm{N}$ ASA sets aggressive, strategic, civil aircraft noise reduction goals to improve the quality of life of millions of people exposed to airport noise. NASA plays a critical role in reducing community noise exposure via technology research and by providing an ambitious noise reduction roadmap for U.S. aerospace industry. Under NASA's Fundamental Aeronautics Program, the Subsonic Fixed Wing Project has adopted a community noise reduction goal for new, subsonic, single-aisle, civil aircraft expected to replace current 737 and A320 airplanes. These so-called "N+1" aircraft - designated in NASA vernacular as such since they will follow the current, inservice, "N" airplanes - are hoped to achieve certification noise goal levels of 32 cumulative EPNdB under current Stage 4 noise limits. ${ }^{1}$ NASA's $\mathrm{N}+1$ noise reduction goal is of national importance, having been accepted by the Federal Aviation Administration for their Continuous Low Emissions, Energy, and Noise (CLEEN) initiative.

NASA has set N+1 goals for other aircraft system performance metrics as well. Relative to B737-800/CFM567B performance levels, goals are set for block fuel burn and takeoff field length reductions of $33 \%$. Additionally, a

\footnotetext{
${ }^{1}$ Aerospace Engineer, Multidisciplinary Design, Analysis, and Optimization Branch, Mail Stop 5-11.

${ }^{2}$ Associate Principal Investigator (Acoustics), Acoustics Branch, Mail Stop 54-3, AIAA Associate Fellow.

${ }^{3}$ Senior Research Scientist, Aeroacoustics Branch, Mail Stop 461, member AIAA.
} 
goal for oxides of nitrogen reduction is set to $60 \%$ below the landing and takeoff emission stringencies set in 2004 by the Committee on Aviation Environmental Protection (CAEP/6). Since these performance metrics are aggressive, contrasting, and often conflicting, achieving goal levels for the noise, emissions, fuel burn, and field length metrics simultaneously may not be possible. These goals therefore represent four distinct "corners" of the airplane design trade space. A balanced, profitable, business-case airplane design may satisfy one or more of these goals, but is unlikely to meet the goal of every metric at once. Even more challenging goals are set for future $\mathrm{N}+2$ and $\mathrm{N}+3$ aircraft.

The -32 cumulative EPNdB N+1 goal was set in 2005 based on an earlier, unpublished, internal NASA study using the best methods and information available at the time. This paper documents a more rigorous investigation conducted in 2008 for the Subsonic Fixed Wing Project using the latest technology data and higher-fidelity analytical tools. It is an in-depth, self-consistent, systems analysis study of an engine and airplane system using accepted NASA tools and methods. The intent of this study is to verify, document, and determine progress towards the -32 EPNdB N+1 goal. This paper describes the analysis of a notional airplane located in the "low-noise corner" of the design trade space. The airplane design showcases an inherently-quiet ultrahigh bypass ratio (UHB) propulsion system combined with innovative, advanced, noise reduction technologies that perhaps would not be used in a business-case design. This report is a more formal documentation of three presentations made at NASA programmatic meetings in $2008 .^{2,3,4}$

This assessment leverages results from a separate NASA system concept study conducted in 2008, in which UHB turbofan engines were examined for a notional, $\mathrm{N}+1$, single-aisle transport. ${ }^{5}$ The objective of the NASA UHB engine concept study was to determine if the fuel consumption and noise benefits of engines having lower fan pressure ratios (and correspondingly higher bypass ratios) translate into overall aircraft system-level benefits for a 737 class vehicle. This internal study provided independent guidance to NASA program management regarding the new PurePower geared turbofans under development by Pratt \& Whitney. ${ }^{6}$

In Ref. 5, the propulsion system design trade space was examined by designing a representative family of 48 $\mathrm{N}+1$ UHB engines, analytically installing them on a common airframe model, and performing aircraft mission performance and sizing analyses. The independent propulsion design parameters investigated were aerodynamic design point fan pressure ratio, overall pressure ratio, fan drive architecture (i.e., direct- or gear-driven), bypass nozzle architecture (i.e., fixed- or variable-geometry), booster compression work split, and cruise Mach number. Engine and airframe technology projections commensurate with a 2015 entry-into-service date were assumed. Aircraft performance characteristics, including properties of the NASA project goal metrics (fuel burn, emissions, field length, and noise) were analytically computed for each vehicle and are reported in Ref. 5.

An interesting and important aspect of the aircraft-engine system not always considered in noise certification predictions is the influence of airplane trajectory and engine throttling on noise. UHB turbofans have significantly different thrust lapse characteristics than other turbofans having higher specific thrust, resulting in takeoff and approach trajectories and throttle settings that must be modeled properly to correctly compute noise. Detailed takeoff and approach trajectory calculations were made for each of the airplanes in Ref. 5. The same trajectory modeling procedures are used to compute certification noise in this study.

One of the quietest propulsion systems investigated in Ref. 5 - a geared turbofan with an ultrahigh bypass ratio is selected for further, refined study and is the basis of this report. It is important to note that this UHB engine is not the best performing propulsion system examined in Ref. 5. That is, of the 48 engine designs studied, it does not result in an airplane having minimum block fuel or takeoff gross weight. Its low fan pressure ratio led to a relatively high engine weight and a large nacelle diameter, resulting in propulsion-airframe integration penalties and poorer overall mission performance. Instead, it is selected in this study because it represents the "low-noise corner" of the design trade space, noting once again that meeting all of the NASA goals simultaneously may not be possible.

\section{Method of Analysis}

The low-noise propulsion system singled out from Ref. 5 for analysis of the noise goal is comparable in thrust class to the CFM56-7B engines now in use on the 737. However, it is a more advanced, geared, UHB turbofan with a lower design fan pressure ratio and lower fan tip speeds than the CFM56. The engine also has a higher overall pressure ratio, better component performance levels, higher hot-section temperatures, lower exhaust velocities, and a higher booster compression split than the CFM56. Once expected to enter service as early as 2015, it appears the 737 replacement aircraft will be delayed for several more years. ${ }^{7}$ Nonetheless, engine component and subsystem performance, cooling levels, and material technologies appropriate for an approximate 2015 service entry date are assumed. Key computed characteristics of the propulsion system at sea level static and standard day conditions are shown in Table 1. The overall pressure ratio is aggressively high (42 at Mach 0.8/35,000 ft, and 32 at sea level static 
conditions) for an engine of this thrust class and comparatively small core. With the low-pressure fan spinning slowly at subsonic tip speeds (only 990 $\mathrm{ft} / \mathrm{s}$ ), a fan-drive gearbox is necessary to avoid low-pressure turbine design complications. Such low-speed, low-pressure fans may have relatively large diameters, presenting potential integration issues. Another consequence of the fan's low pressure ratio requires the engine cycle to have some means of variable geometry in the bypass stream to maintain proper fan operability and safety margins. A variable-area bypass nozzle is used to maintain a constant surge margin throughout the operating envelope. The thermodynamic engine cycle performance is analyzed using the Numerical Propulsion System Simulator code $\left(\mathrm{NPSS}^{8,9}\right)$. NPSS is a variable-fidelity, object-oriented, engine cycle analysis tool developed jointly by NASA and U.S. industry. It is currently the accepted, state-of-the-art software for airbreathing engine cycle performance analysis for U.S. aerospace industry, academia, and NASA. A multiple design point analysis is performed on the engine cycle in order to meet several performance requirements such as airplane thrust demand at rolling takeoff and top-of-climb conditions, as well as to set flow rates, cycle temperatures, pressures, spool speeds, and cooling levels. The bypass ratio is a fallout of the fan pressure ratio and pressure levels in the bypass and core exhaust ducts at the cycle's aerodynamic design point. Aeromechanical design, flowpath, and engine weight analyses are performed with the Weight Analysis of Turbine Engines code $\left(\mathrm{WATE}^{10}\right)$. WATE has been significantly upgraded since its initial introduction in the 1970s and is currently implemented as a suite of NPSS interpretive analysis elements. At NASA, WATE is coupled with NPSS to provide a complete modeling capability of turbofan engines. Additional details on the engine design may be found in Ref. 5 .

The notional N+1 airplane is based on an analytical evolution of the currently-in-service Boeing 737-800 with winglets. In Ref. 5, a reference 737 analytical model was developed based on publicly-available 737-800 geometry, weight, and performance information; proprietary low-speed and clean-configuration aerodynamic data; and a NASA NPSS representation of the CFM56-7B engine. The CFM56-7B was analytically modeled in NPSS using data available from several public-domain sources, such as FAA type certification data sheets, manufacturerprovided operating documents, technical reports, Jane's Aero Engines, and manufacturer's websites. No companyproprietary data were used. The reference 737 carries 262 passengers in a single-aisle, two-class seating arrangement. The aircraft synthesis was carried out using NASA's Flight Optimization System (FLOPS ${ }^{11}$ ) computer program. Minor calibrations to the FLOPS-computed component weights and aerodynamics were performed to match published operating empty weight and range capability of $3060 \mathrm{~nm}$ at a 32,400 $\mathrm{lb}$ payload. The FLOPS model was set up to perform a basic wing-engine sizing analysis. Scaling the wing and engine sizes of the reference model for minimum takeoff gross weight subject to active aircraft performance constraints led to results that were consistent with the actual 737 aircraft. The 737 model was further developed to include detailed, low-speed takeoff and landing assessments using FLOPS's built-in, time-stepping trajectory analysis module. Compliance with the airworthiness requirements described in Part 36 and 25 of the Federal Aviation Regulations (Refs. 1 and 12, respectively) is observed. Takeoff and landing performance data ${ }^{13}$ for standard day, dry runway conditions were used for validation of the FLOPS low-speed trajectory model. Takeoff and landing distances matched to within approximately one percent of the reported values.

To evolve the reference 737 into the advanced $\mathrm{N}+1$ vehicle model, the design cruise Mach number is increased from 0.785 to 0.800 , with an appropriate increase in wing sweep to reflect the higher airspeed. The wing aspect ratio and taper ratio are unchanged. The 262-passenger, mixed-class, single-aisle cabin arrangement is maintained, but the design range at the $32,400 \mathrm{lb}$ payload point is increased from $3060 \mathrm{~nm}$ to $3250 \mathrm{~nm}$. The performance improvements in airspeed and range are considered appropriate for a future vehicle in this class. Broad use of composite structural materials is assumed relative to the all-metal construction of the 737. Composite construction of primary structures is assumed to result in a $15 \%$ reduction in the component weights computed for the wing, fuselage, and empennage. This is comparable to the structure of the new Boeing 787, where as much as 50 percent of the primary structure is made of composites. ${ }^{14}$ Additional technology improvements

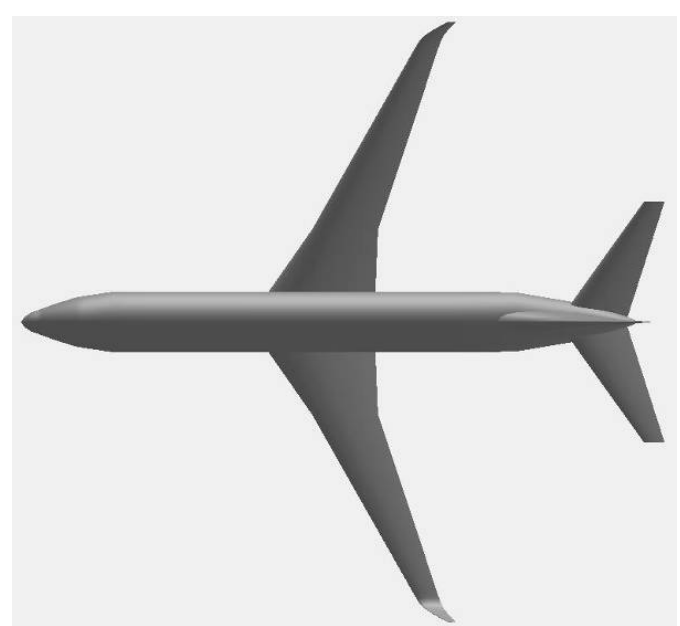

Figure 1. Planform view of the $\mathrm{N}+1$ airplane. 
similar to those found on the 787 include an increase in hydraulic pressure to 5000 psi and a $1 \%$ reduction in drag due to trailing edge variable camber and drag clean-up. A Vehicle Sketch Pad ${ }^{15}$ planform schematic of the $\mathrm{N}+1$ vehicle (without engines) is shown to scale in Fig. 1.

Propulsion-airframe integration effects are important to address properly for large-diameter UHB engine nacelles. Low-speed, low-pressure fans - such as the 82-inch diameter fan considered here - present unique propulsion-airframe integration challenges. Nacelle drag, ground clearance, windmilling drag, vertical tail sizing, thrust reverser operation, engine placement, and gear length and weight issues are considered. The methods used to capture these effects are described in greater detail in Ref. 5. Like the reference 737 model, the N+1 vehicle model is parametrically sized for minimum takeoff gross weight, and detailed takeoff and landing trajectories are computed.

The noise analysis approach, methods, assumptions, and tools used in this study have been examined by acoustics experts at NASA Glenn, NASA Langley, U.S. industry, and academia as part of a comprehensive, multifidelity, NASA acoustic tool benchmarking activity. ${ }^{16}$ Efforts to benchmark the accuracy of NASA's aircraftsystem-level noise prediction code for airport community noise are also leveraged. ${ }^{17}$ This computer code - the Aircraft Noise Prediction Program (ANOPP, Release Level 26) ${ }^{18,19}$ - is a systems-level code used in this study to compute certification noise for the $\mathrm{N}+1$ vehicle. The certification noise predictions of the reference 737 described in Ref. 17 serve as a validation of the methods and tools used in this $\mathrm{N}+1$ vehicle study.

Freefield, lossless, $1 / 3^{\text {rd }}$ octave band frequency component source noise levels are computed using predictive modules within ANOPP. The UHB engine's thermodynamic, aeromechanical, and geometry data are used as inputs to ANOPP's propulsion source noise prediction methods. At NASA, the NPSS and WATE airbreathing component element libraries have functions, viewers, and case files coded in interpretive language to produce engine data to be used as ANOPP input parameters. These so-called "engine state tables" are the preferred method to transfer engine state data to ANOPP's source noise prediction modules. Engine state data - consisting of pressure, temperature, flow area, spool speed, and fuel and air flow rates - are computed by NPSS for a range of airspeeds, altitudes, and throttle settings at standard acoustic day (ISA $+18^{\circ} \mathrm{F}$ ) conditions. As the airplane traverses its flight path, engine data at the appropriate airspeed, altitude, atmospheric conditions, and throttle setting are interpolated from the state tables and are delivered to the source noise prediction modules.

The UHB engine's jet noise sources are predicted using the Stone method. ${ }^{20}$ This method - implemented in ANOPP's "ST2JET" module - is perhaps the best semi-empirical jet noise prediction method developed to date. It uses an innovative, physics-based, Bayesian regression of jet acoustic data that seamlessly spans various nozzle flow and geometry regimes. It is calibrated against jet acoustic data collected from several types of axisymmetric nozzle designs, such as single-flow and coannular nozzles, plug and plugless nozzles, and convergent and convergentdivergent nozzles. The method is considered in the acoustic tool benchmarking activity described above to be accurate. ${ }^{21}$ Coannular nozzles with bypass ratios of up to 15 are part of Stone's calibration, and is therefore considered quite applicable to UHB engines. The method accepts nozzle flow characteristics as input parameters from the engine state tables described above. The Stone method also captures the noise-reduction effects of nozzle perimeter-mixing devices, such as chevrons. This feature of the method is based on 1997 acoustic measurements of chevron-equipped nozzles from NASA Glenn's Aeroacoustic Propulsion Laboratory's Nozzle Acoustic Test Rig freejet facility. ${ }^{22}$ The Stone perimeter-mixing method predicts reductions in large- and intermediate-scale jet mixing noise and an increase in small-scale (high frequency) jet mixing noise near the nozzle exit plane. Some inaccuracies of the Stone perimeter-mixing method for certain nozzle designs to which the method was not calibrated are noted in Ref. 21. However, since the N+1 UHB nozzle is coannular with an external plug, and is much the same as the chevron nozzles used in Stone's regression calibration (i.e., the "3IB" and "3IC" coannular nozzle configurations of Ref. 22), the method is considered accurate for use here. Chevrons are assumed present for the UHB engine's central core nozzle. However, chevrons are not applied to the bypass nozzle due to potential conflict with the actuation system needed for the variable-area bypass nozzle design. The $\mathrm{N}+1$ UHB nozzle is proposed to be similar in architecture to the 3IB nozzle test configuration (with a nominal bypass ratio of 5) shown in Fig. 2 , but with a much higher bypass ratio. The 3IB nozzle has 12 in-flip core chevrons and - unlike the 3IC nozzle - no outer bypass chevrons.

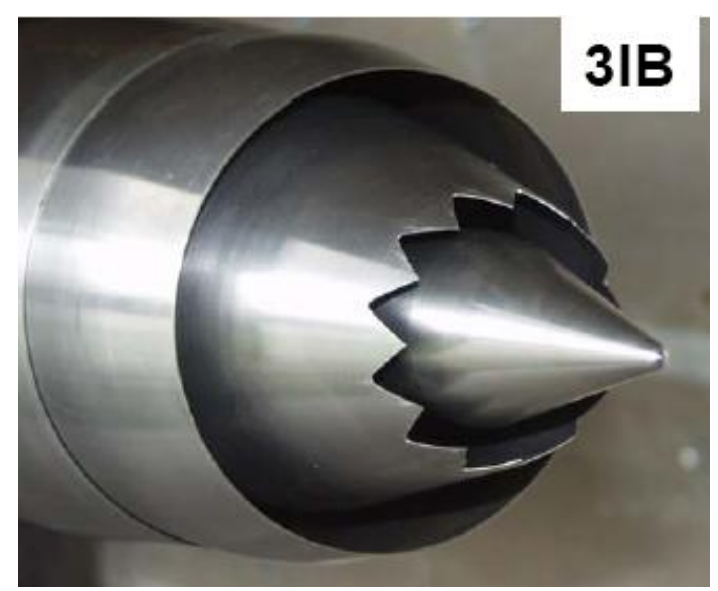

Figure 2. 3IB chevron coannular nozzle model. 
The UHB engine fan noise source is modeled using experimental acoustic data collected from a scale-model fan test article in NASA Glenn's $9 \mathrm{ft}$ by $15 \mathrm{ft}$ Low Speed Wind Tunnel (LSWT). ${ }^{23}$ The fan tested is a 22 -inch diameter model of Pratt \& Whitney's Advanced Ducted Propulsor, shown in Fig. 3. Ordinarily in an aircraft system noise prediction problem, fan source noise would be computed using one of ANOPP's built-in methods. Indeed, in the study upon which our engine is based (Ref. 5), fan noise was modeled using ANOPP's internal General Electric empirical method, ${ }^{24}$ which is considered to be generally accurate. ${ }^{25}$ Using a built-in method is convenient in an aircraft systems study, since system effects such as fan operation, speed, scale, and convective amplification effects that vary with fan design, engine throttle position, and flight condition are properly accounted for by the model without need for user intervention. A built-in method is particularly helpful when performing a design space exploration of

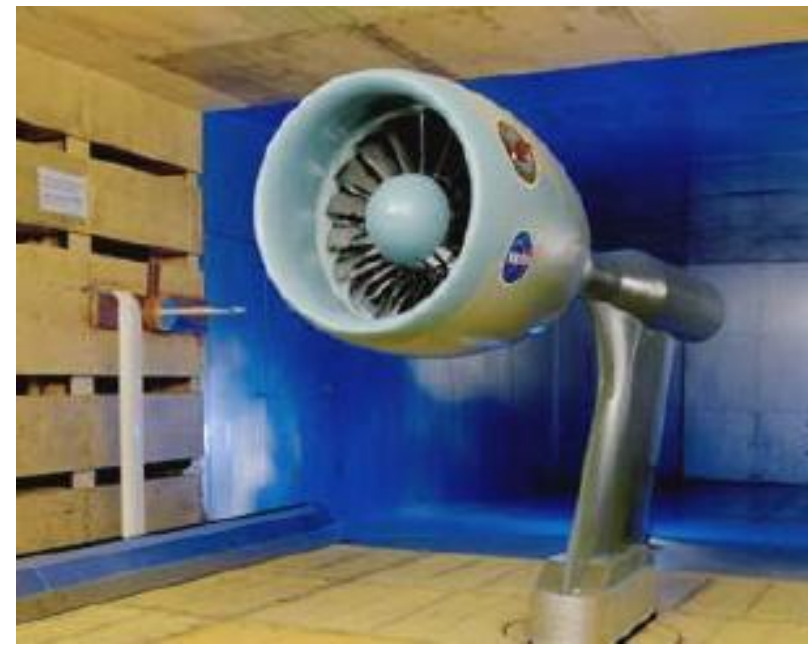

Figure 3. Scale model Advanced Ducted Propulsor "Fan 1" test article installed in the NASA LSWT. an engine architecture such as in Ref. 5, where fan design parameters such as pressure ratio are parametrically varied. However, while the method described in Ref. 24 may be appropriate to predict noise during a design space exploration of many fans, greater accuracy may be obtained if the fan to be analyzed is very similar to a fan already tested in an aeroacoustic facility. Moreover, the Advanced Ducted Propulsor "Fan 1" tested in the LSWT is representative of modern, contoured, wide-chord fans for high-bypass engines, whereas the built-in ANOPP methods are calibrated to older, narrow-chord, straight-bladed fans. Fan 1 is an 18-blade, high bypass, scale-model fan with a low design pressure ratio of 1.29. This stage pressure ratio compares well with the 1.30 pressure ratio of our N+1 UHB fan at similar conditions, and the blade count is also identical. Although the fan loadings are different (the UHB fan of Ref. 5 and the scale model Fan 1 SLS corrected tip speeds are $990 \mathrm{ft} / \mathrm{s}$ and $840 \mathrm{ft} / \mathrm{s}$, respectively), spool speed in thermodynamic cycle analysis is only an artifice when scaled component performance maps are used. To use the noise measured from the Fan 1 test article, the tacit assumption is that the N+1 UHB fan is operating at the lower, $840 \mathrm{ft} / \mathrm{s}$, corrected takeoff tip speed. There are, of course, aeromechanical, flowpath, and weight implications that cannot be so easily ignored, but the engine cycle performance is unchanged.

The measured noise levels of Fan 1 were collected and reduced to lossless, freefield, $1 / 3^{\text {rd }}$ octave band spectra by methods described in Ref. 23. These spectra must be modified further before they may be used in an aircraft system noise problem. First, an atmosphere-dependent source strength correction is applied to bring the levels from facility conditions to standard atmospheric pressure and temperature. Sources other than pure fan noise (such as lowfrequency airflow scrubbing and facility noise sources, and high-frequency measurement anomalies) are subtracted from every spectrum. The levels are adjusted from model-scale, 22-inch fan diameter to full-scale, 82-inch diameter by applying amplitude and frequency shifts. Finally, convective amplification Doppler effects are added as the spectra are analytically "flown" at variable airspeed, ranging from static to Mach 0.4. The end result is a table of fan noise levels, with discrete independent parameters consisting of 51 emission polar (yaw) angles, 8 shaft speeds, and 5 flight Mach numbers. The source is assumed to be symmetric in emission azimuthal (roll) angle. The spectra are tabulated for interpolation and fed into the aircraft system noise simulation via ANOPP's Acoustic Data Module; a feature that allows users to create their own noise sources to be used instead of using ANOPP's internal source noise prediction methods. 
The acoustic data collected from Fan 1 are hardwall; i.e., no acoustic treatment is present. Conventional inlet, interstage, and aft fan duct liners are applied to reduce fan inlet and discharge noise. The benefits of these liners are modeled by applying an acoustic suppression performance "map" of $1 / 3^{\text {rd }}$ octave band sound pressure level decrements to the hardwall fan source spectra. This approach differs from the 737 800/CFM56-7B validation study described in Ref. 17 - where ANOPP's built-in treatment suppression prediction module was used $^{26}$ - since a more aggressive treatment configuration would likely be used in an advanced UHB engine. The liner suppression map is based on measured wind tunnel data from the 22-inch diameter Fan 1 rig in NASA's LSWT. ${ }^{27}$ The most effective treatment tested proved to be double degree of freedom liners applied to the inlet, interstage, and aft bypass duct areas. These liners are tuned to attack the discrete interaction tone's second harmonic at maximum takeoff-rated power. An initial treatment suppression map is generated based on the measured differences between the treated and hardwall measurements. This simple map is scaled from the 22-inch model dimensions to 82-inch diameter full scale using standard regulation frequencies. The data are smoothed with a regression technique to fit a modified Weibull probability density function as shown in Fig. 4. A Weibull-shaped curve is chosen since liner effectiveness is small at low frequencies and increases to a maximum near its tuned frequency. Low-frequency liner self noise - caused by air flow and surface roughness, and can be seen in the Fig. 4 - is small and is ignored by this regression. The logarithm of the ratio of inlet diameter to wavelength is an appropriate regression choice for the independent parameter. The complete treatment suppression map is shown in Fig. 5. Maximum effectiveness is approximately $12 \mathrm{~dB}$ at an emission polar (yaw) angle of 99 degrees from the inlet.

Further adjustments representing fan noise reduction technologies are made to the hardwall fan source noise spectra prior to propagation. In addition to conventional fan liners, two advanced technologies are applied: soft vane stators $^{28}$ and over-the-rotor foam metal treatment. ${ }^{29}$ Both of these technologies are applications of acoustic treatment in areas of the engine which currently do not have treatment: on the surface of the fan vanes and above the fan rotor tips. Soft vane stators have small Helmholtz resonator chambers inside the airfoils and are covered by a porous surface material. This single-degree-of-freedom treatment reduces the unsteady, noise-generating, pressure fluctuations like other turbofan treatment panels, but acts directly on the vanes. Over-the-rotor foam metal is a bulk sound-absorbing material situated over the fan rotor where, normally, conventional fan rub strips are located. The metal foam is integrated with the fan casing containment structure and provides a greater effective treatment area. An illustration of these two technologies is shown in Fig. 6. 


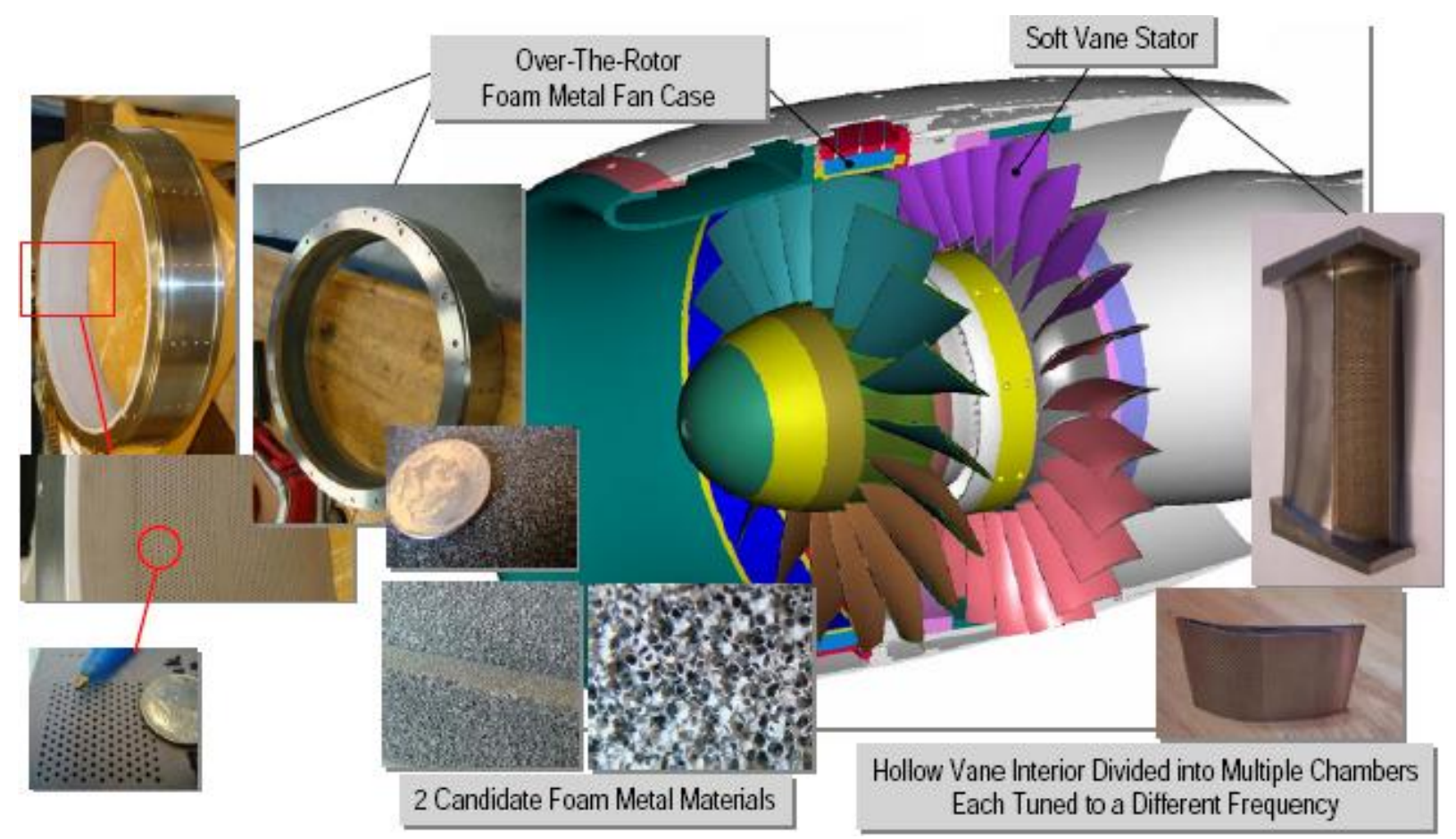

Figure 6. Advanced fan noise reduction technologies: over-the-rotor foam metal bulk treatment (left) and soft vane stators (right).

These technologies are anticipated to have matured enough for incorporation in the UHB engine assumed in this study. These technologies are also assumed to be relatively lightweight, inexpensive, low-maintenance, and free of aerodynamic performance penalties such that an engine manufacturer would be willing to make use of them on their product. The treatment in these locations attenuates both fan broadband and interaction tone noise and are anticipated to work together without conflict to produce additive fan noise reduction benefits. Acoustic tests of both of these technologies were conducted at NASA Glenn in 2008. Based on these tests, a system-level decrement of -4 $\mathrm{dB}$ is applied to the freefield hardwall fan source noise levels. This adjustment is applied as a simple constant to the fan sound pressure levels - already reduced by the conventional liners - across all $1 / 3^{\text {rd }}$ octave band frequencies, directions, and throttle settings.

The remaining propulsion noise sources considered are combustion, turbine, and compressor noise; often collectively known as core noise. Historically in noise certification, core noise tends to be significant only at the approach certification point. Core noise is revealed at low, approach throttle settings when fan and jet noise are reduced due to lower fan tip speeds and lower nozzle exhaust velocities. A fundamental turbine discrete interaction tone may also fall under $10 \mathrm{kHz}$ at approach throttle and may become problematic. In advanced UHB engines, however, core noise may become significant at higher throttle settings as well, since jet and fan noise are lower due to increased bypass ratio, low fan tip speeds, and modern, more effective noise reduction technologies. Accurate core noise modeling for UHB engines is essential. Core noise is predicted using ANOPP's built-in procedure (the "GECOR" module) developed by Emmerling ${ }^{30}$ and later modified by Ho. ${ }^{31}$ Preliminary results from NASA's current acoustic tool benchmarking study (Ref. 16) indicate that the ANOPP method agrees well with static core noise separated from the overall acoustic signature of the Honeywell TECH977 business-jet-class research engine. ${ }^{32}$ General Electric also evaluated the ANOPP core noise method favorably in 1996 based on static acoustic test comparisons to CF6-80C2, QCSEE, and E3 engines, as well as comparisons with their own proprietary method (Ref. 24). Like the Stone jet noise method, data are fed into ANOPP's core noise module via engine state table data. Key input parameters are maximum cycle pressure, temperature, and flow rate. A shortcoming of the ANOPP core noise method is that the maximum overall pressure ratio allowed is 30 . This is not unexpected since the method dates to the 1970s and was calibrated against engines then having much lower overall pressure ratios. The N+1 UHB engine produces a SLS pressure ratio of 32 (already over the ANOPP limit; see Table 1), and increases to approximately 34 at an airspeed of $180 \mathrm{ktas}$; roughly corresponding to the flight condition just before the throttle 
cutback beyond the lateral certification observer. The core noise therefore may be under predicted by an unknown amount. No core noise reduction technologies are assumed.

Like engine core noise, airframe noise sources ordinarily tend to be significant only during approach, when engine throttle settings are reduced. With advanced, quiet, UHB engines, however, airframe noise sources may be expected to be more prominent at approach, and at higher throttle settings as well, since they may become audible over the already-low fan and jet noise sources. In addition, for practical reasons and safety considerations, air traffic on approach tends to fly over significant distances at comparatively low altitude. This is in sharp contrast to departure trajectories, where the pilot's intent is to gain altitude rather quickly. Remarkably, despite having much louder noise signatures on departure than on approach, this behavior results in noise "footprints" that have roughly equivalent enclosed areas on approach and departure. These considerations point to the need for aggressive airframe noise reduction technologies for UHB-equipped aircraft. Freefield, lossless, $1 / 3^{\text {rd }}$ octave band spectra for flap, slat, landing gear, and trailing edge airframe noise sources are predicted using a method developed in 1977 by M.R. Fink of the United Technologies Research Center for the FAA. ${ }^{33}$ The Fink method - programmed into ANOPP's "FNKAFM" module - accepts gross airframe dimensions such as span, flap chord lengths, and gear configuration and dimensions; all of which may be obtained from a simple, open-literature, three-view aircraft drawing. Scrutiny of portions of the Fink method to date has not yet revealed any fundamental issues. ${ }^{34}$

The airframe noise reduction technologies applied to the N+1 airframe are aggressive and substantial - fair game, since this study assesses the "low-noise corner" of the aircraft design trade space. These technologies are currently considered somewhat immature, but with aggressive funding and development, they could become available in time for the $\mathrm{N}+1$ vehicle's entry into service. The high-lift flap arrangement on the $\mathrm{N}+1$ aircraft is assumed to consist of retractable, inboard- and outboard-segmented, slotted flaps. Unlike conventional trailing edge flaps, however, the N+1 flaps are assumed to be equipped with continuous moldline links. These links abate the aerodynamic noise generated by airflow around the discontinuous flap side edge by extending and continuously fairing a flexible moldline into the wing trailing edge. A flow analysis ${ }^{35}$ illustrating the mechanism and the effect on flap side-edge streamlines is shown in Fig. 7. The ordinarily strong vortex system is diffused by the moldline, thus reducing noise. The noise benefit of continuous moldline links is modeled by subtracting 8 $\mathrm{dB}$ from the conventional flap noise computed by the Fink method. Until this technology matures and its impact is better understood, the benefit is assumed constant across all $1 / 3^{\text {rd }}$ octave band frequencies, directions, and airspeeds.

Another source of aerodynamic noise radiates from the extended leading edge slat cove. Slat noise results from complex flow patterns in the slat cove region. If these turbulent, circulating, vortex-shedding flow patterns are largely prevented from developing, while still maintaining uniform flow through a slat slot, substantial noise reduction benefits may be achieved. An example of a flexible material filling the cove of a bench top slat model is shown in Fig. 8. The noise benefit of slat cove filler is modeled by subtracting $10 \mathrm{~dB}$ from the conventional slat noise computed by the Fink method; constant across frequency, direction, and airspeed.

The main gear and nose gear are assumed to have spoilers for flow deflection and fairings to improve the aerodynamic shape while still allowing easy access for maintenance and inspection. In addition, trailing edge treatment methods are assumed, such as serrated edges or brushes, to reduce trailing edge noise. A graph of the assumed benefits of these and the other airframe noise reduction technologies are shown in Fig. 9.

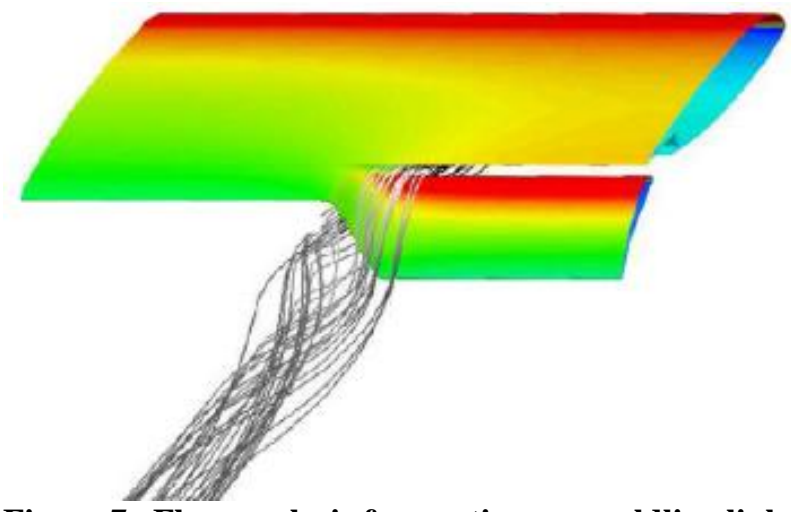

Figure 7. Flow analysis for continuous moldline link, showing surface pressure and side-edge streamlines.

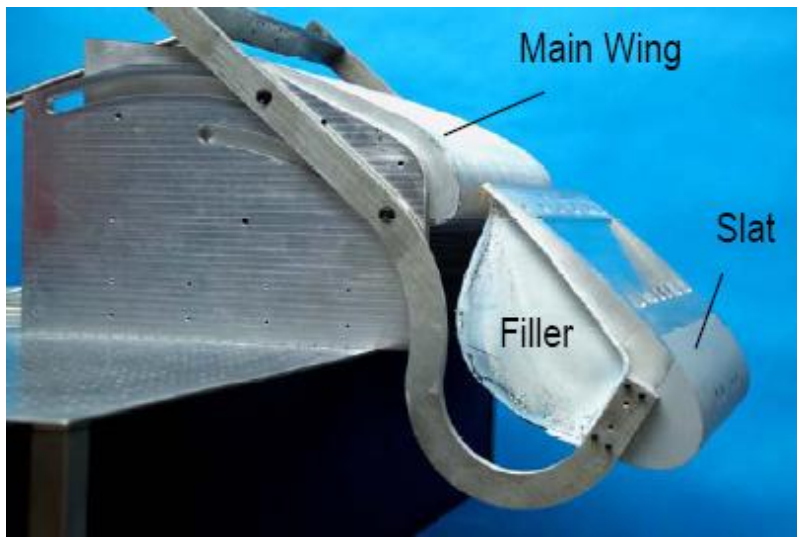

Figure 8. Example of a pneumatic slat cove filler technology concept (bench top model). 
Using an assumption of acoustic superposition, the freefield, lossless spectra for all of the noise sources described above are analytically summed in the vicinity of the aircraft. Real noise sources are, of course, complex, distributed signals that are affected by other acoustic sources, aircraft external surfaces, and the environment. No provisions are made to adjust the component spectra for acoustic near-field phenomena such as source interactions, reflections, refraction, diffraction, or other effects.

The summed spectra are propagated to the three certification observers on the ground in accordance to the specifications for certification measurements. Noise propagation effects accounted for include spherical spreading, Doppler shift and convective amplification, atmospheric attenuation, ground reflections based on data for

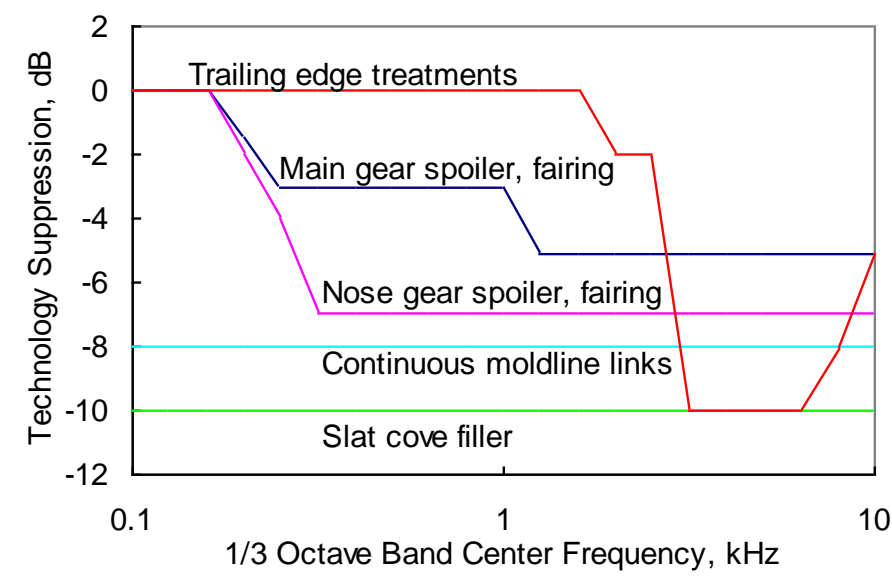

Figure 9. Airframe noise reduction technology benefits. grass-covered ground, and extra ground attenuation. More complex propagation phenomena such as scattering, weather effects, and terrain are unaccounted for. The airplane trajectory, computed as described earlier, is fed into the ANOPP simulation. Vector geometry analyses for the airplane relative to the three certification microphone measurement locations - shown in Fig. 10 - are performed within ANOPP as functions of source time. Note that in the interest of international rulemaking terminology harmonization, the former "sideline" certification location term has been deprecated in favor of "lateral," as has "takeoff" to "flyover." In any event, the propagated acoustic spectra are predicted at half-second intervals at each of the three certification locations. From these spectra, ANOPP computes OASPL, PNL, PNLT, and other noise metrics of interest as functions of observer time. The EPNL certification noise metric is computed from the PNLT-time noise history at each observer as prescribed in Ref. 1.

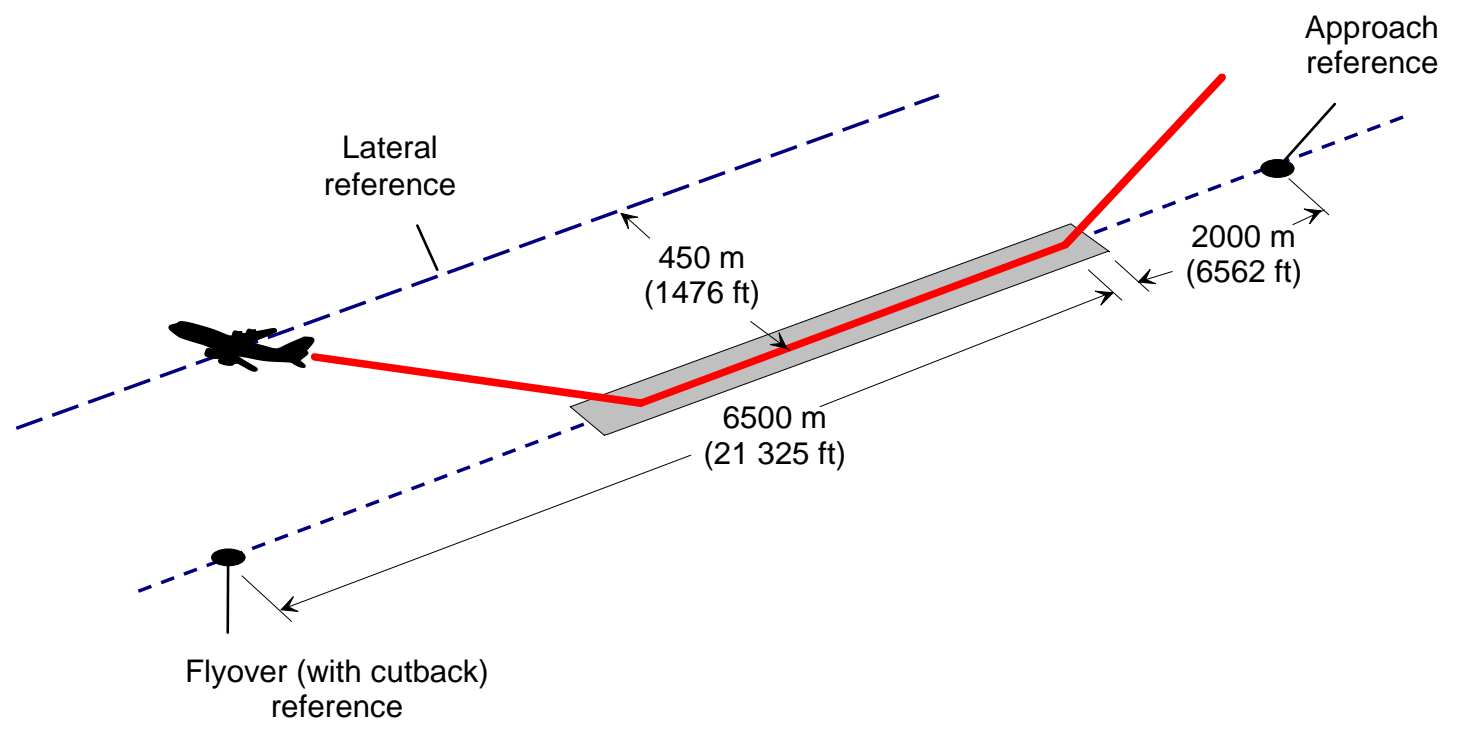

Figure 10. Noise certification observer arrangement relative to hypothetical combined takeoff and landing aircraft trajectories.

\section{Results and Discussion}

As noted, the UHB engine selected from those studied in Ref. 5 for refined study here represents the "low-noise corner" of the airplane design trade space. As such, it has a very low design fan pressure ratio, exhaust velocities, and it has quite different specific thrust characteristics than the turbofans used on present-day, next-generation 737s. The CFM56-7B series turbofan, used on the next-generation 737-600, $-700,-800$, and -900 models, has a runway ground roll net thrust lapse (i.e., from zero to $170 \mathrm{ktas}$ at sea level) of about only $20 \%$. The UHB engine analyzed here has a runway thrust lapse of nearly $30 \%$. Note that not all UHB engines would lapse this much in thrust; it may 
be that a UHB engine design enabling a better business-case airplane design might not lapse much more than the CFM56-7B. However, our low-noise UHB engine behaves significantly different, resulting in takeoff and approach trajectories and throttle settings that must be modeled properly to correctly compute certification noise. This is in contrast to many other certification noise estimates in the conceptual phase of aircraft design, where fixed trajectories and throttle settings are often assumed based on previously-collected data from other representative aircraft. Trajectory data computed for the $\mathrm{N}+1$ airplane and the 737-800 for altitude, airspeed, and throttle setting are shown in Fig. 11, Fig. 12, and Fig. 13, respectively. The trajectories shown are presented as "analytical touch-and-

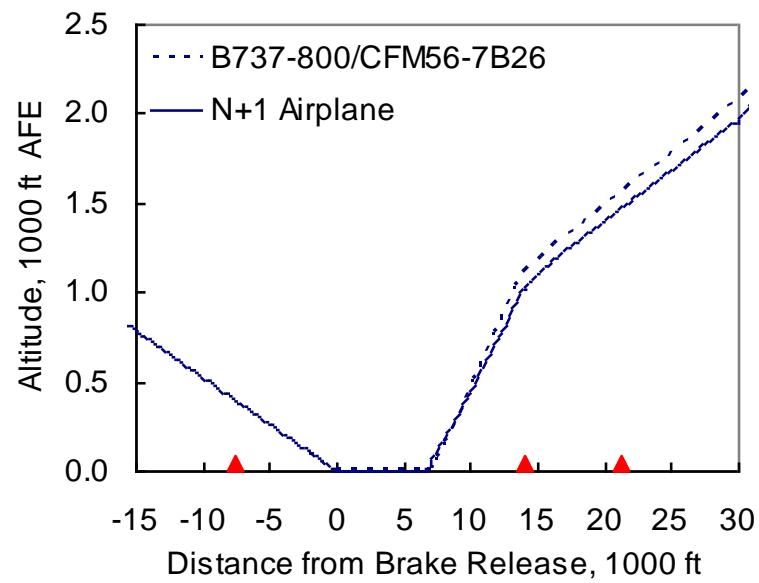

Figure 11. 737 and $\mathrm{N}+1$ trajectory comparison; altitude.

go" operations with both takeoff and landing data shown simultaneously. For presentation purposes, the touchdown point on landing is coincident with the point of brake release on takeoff. Calculations are made for a sea level runway at standard acoustic day (ISA $+18^{\circ} \mathrm{F}$ ) conditions. The airframe noise reduction technologies noted above are assumed to have no impact on the lowspeed aerodynamic performance of the airplane. The triangular markers on each plot denote the noise certification measurement locations.

The approach microphone markers are shown in the figures at $6562 \mathrm{ft}(2000 \mathrm{~m})$ behind the runway threshold (i.e., behind the location of the $50 \mathrm{ft}$ landing obstacle), and $7518 \mathrm{ft}$ from the touchdown point on the runway centerline. Note that in Fig. 13, the UHB engine throttle setting must be set higher than the CFM56-7B (in percent thrust) in order to maintain a 3-degree approach glide slope.

The lateral microphone markers are shown in the figures at 14,000 ft from brake release, on a lateral sideline displacement distance of $1476 \mathrm{ft}(450 \mathrm{~m})$ from the runway centerline. The 14,000 ft location corresponds to the distance from brake release where the airplane has reached $984 \mathrm{ft}$ (300 m) AFE, as permitted - when approved - by regulation B36.3.a.1 (Ref. 1). A check of other lateral locations less than and greater than $14,000 \mathrm{ft}$ from brake release confirms that peak lateral EPNL does in fact occur approximately at the 14,000 ft location. Note that in Fig. 12, the airspeed of the N+1 airplane is 12 ktas slower than the 737 at that point, leading to a longer dwell time for the $\mathrm{N}+1$ airplane and causing the duration component of the lateral EPNL to increase somewhat.

The flyover microphone markers are shown in the figures at $21,325 \mathrm{ft}(6500 \mathrm{~m})$ from brake release on the runway centerline. A noise abatement throttle cutback is used. The engine climb thrust at this point is reduced to the minimum level permitted by regulation (i.e., Ref. 1 requires a minimum climb gradient of four percent with both engines operating, or level flight with one engine inoperative.). The throttle cutback takes place between 16,000 ft and $17,000 \mathrm{ft}$ from brake release. Note the power cutback takes place at approximately $1200 \mathrm{ft}$ AFE. This is above the minimum altitude permitted (i.e., $984 \mathrm{ft}$, or $300 \mathrm{~m}$ AFE for a twinjet), in an attempt to gain additional altitude 
and minimize the noise at the flyover observer. Note that the UHB engine throttle cutback is shallower than the CFM56-7B (in percent thrust) in order to maintain the necessary minimum cutback climb gradient. The altitude that the $\mathrm{N}+1$ airplane is able to reach at the flyover observer is $80 \mathrm{ft}$ lower than the 737, resulting in a noise increase of perhaps $0.4 \mathrm{EPNdB}$. The $\mathrm{N}+1$ airplane's lower acceleration reduces flyover airspeed (by $16 \mathrm{ktas}$ ) and contributes to an increased flyover EPNL duration component.

If the trajectory and throttle settings had been assumed from previous experience rather than calculated, the effects noted above may result in under predicting each of the three EPNLs. If 737 trajectory and throttle settings had been used for the $\mathrm{N}+1$ UHB airplane, its certification noise would have been underestimated by nearly 2 cumulative EPNdB.

The computed trajectories and throttle settings are used to determine engine and aircraft state information. This information in turn is used to predict component source noise spectra as described above for half-second time intervals along the trajectory. The spectra are propagated, and the OASPL and PNLT noise-time histories are plotted in Fig. 14, Fig. 15, and Fig. 16 for the approach, lateral, and flyover observers, respectively. Observer time relative
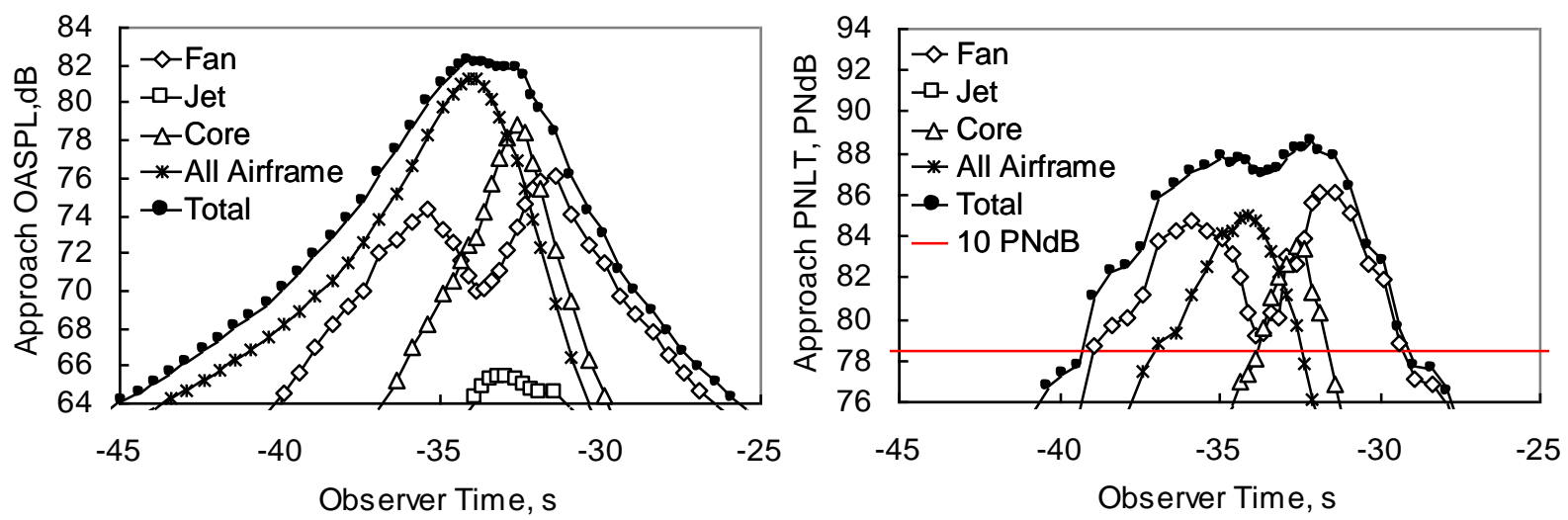

Figure 14. Approach observer OASPL noise-time histories (left), and PNLT noise-time histories (right).
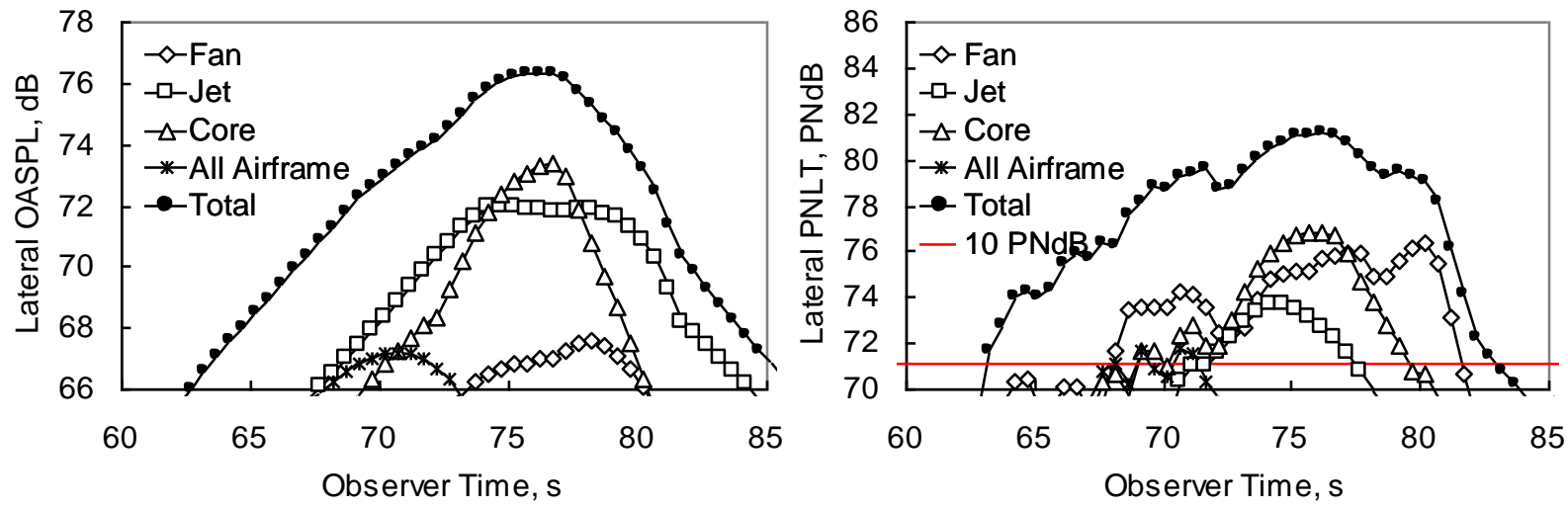

Figure 15. Lateral observer OASPL noise-time histories (left), and PNLT noise-time histories (right).
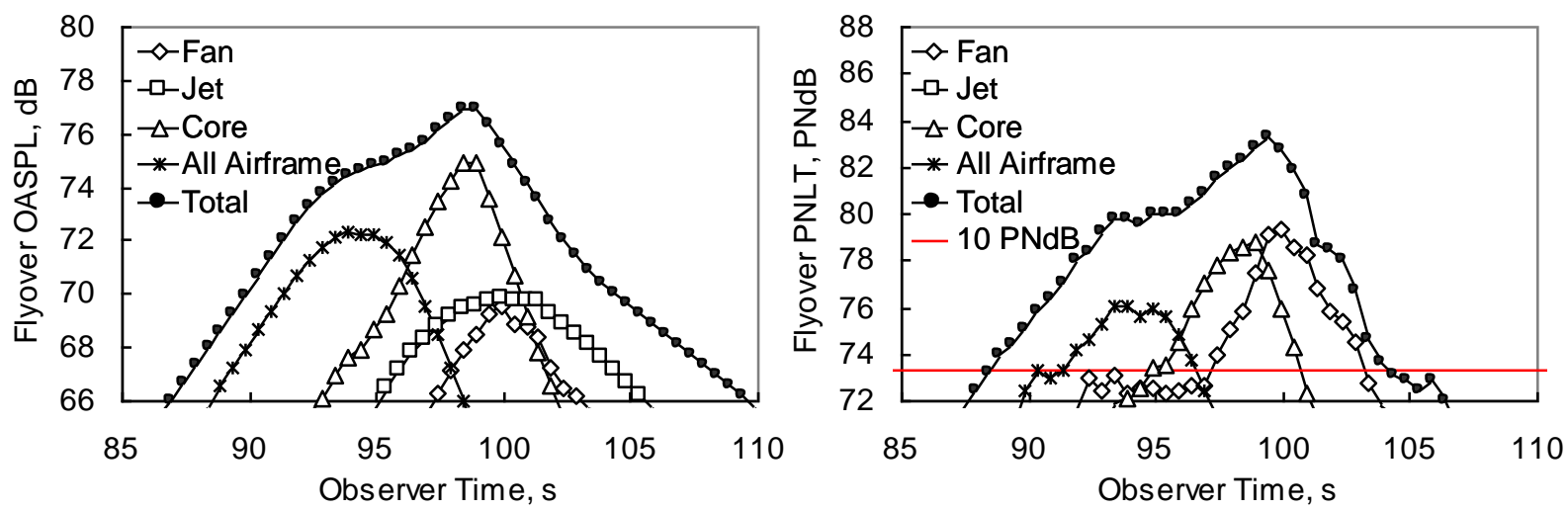

Figure 16. Flyover observer OASPL noise-time histories (left), and PNLT noise-time histories (right).

11 of 15

American Institute of Aeronautics and Astronautics 
to the point of brake release (or touchdown) is used as the independent parameter in each figure. In the analytical world, it is easy to compute each noise source separately from the others simply by issuing appropriate commands to ANOPP. Plotting the levels of each source as a function of time provides additional insight to the overall problem. The OASPL metric is shown at the left in each figure because of its simplicity and its ability to clearly show the smooth rise and fall of each noise source over time. The PNLT metric - shown at the right in each figure - has qualities that capture level, frequency weighting, and tone annoyance penalties. Its time histories are therefore much more irregular than the OASPL histories: as the airplane approaches and recedes, Doppler and convective amplification effects have an effect on the PNLT metric's frequency-weighting and tone penalties. The PNLT-time histories within the integration region of 10 PNdB from the maximum PNLT (shown as a horizontal line in each right-hand figure) are the regulatory bases for the EPNLs shown in Fig. 17.

The approach observer seems to be clearly dominated by the several airframe noise sources on an OASPL basis (Fig. 14, left), with core noise apparently making a significant contribution as well. However, when the higher-frequency fan noise and fan interaction tone contributions are considered via the PNLT metric (Fig. 14, right), fan noise becomes the dominant approach source. Another reason for the fan's strong showing is that the acoustic signature of the Advanced Ducted Propulsor "Fan 1 " is dominated by strong aftquadrant noise levels (See Ref. 23.). This results in two PNLT peaks within the area of integration. The first peak consists of fore-quadrant fan

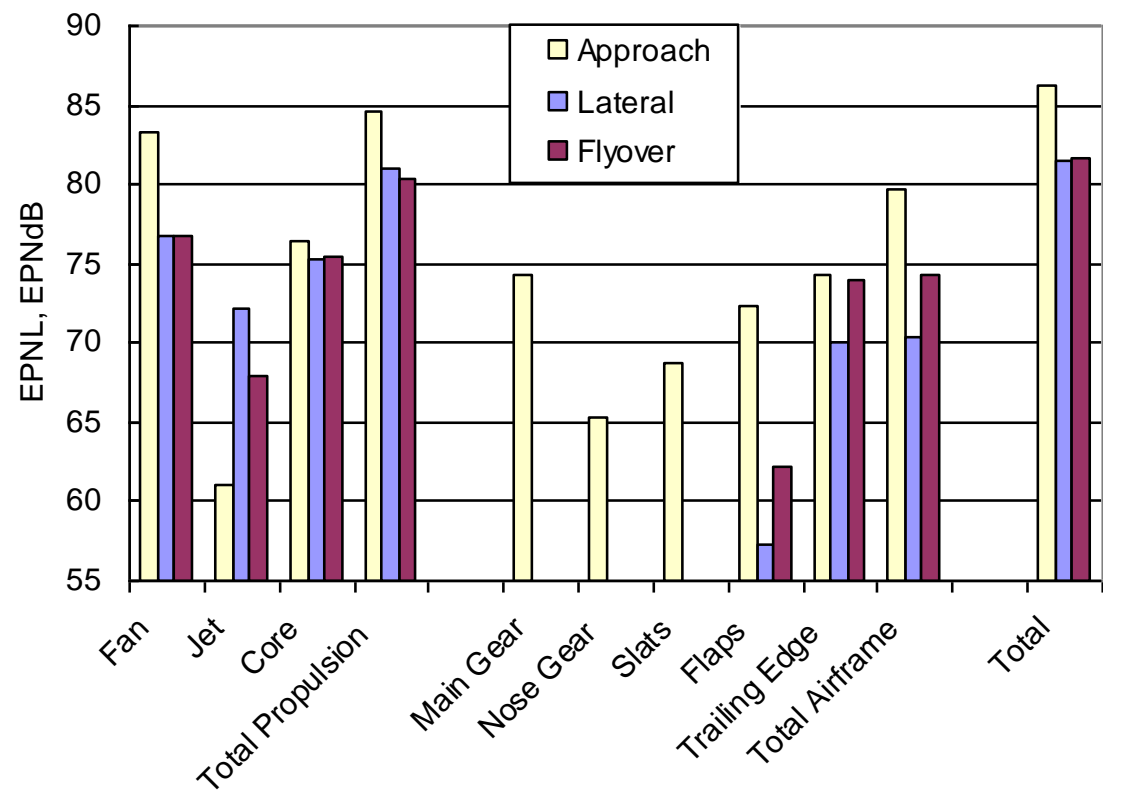
noise increased by convective amplification, while the second, aft-quadrant fan noise peak rises despite the favorable convection effects of the receding aircraft. The strong aft fan noise extends the PNLT trace for several seconds beyond the airframe noise sources and increases the approach EPNL duration component. The airframe noise sources - effectively muted by their noise reduction technologies - make a secondary contribution to the approach EPNL. Core noise becomes a minor contributor on a PNLT basis, and jet noise at the approach power setting is insignificant relative to the other sources with any metric. The overall approach EPNL is 86.2 EPNdB.

The lateral observer is dominated by jet noise, and - perhaps surprisingly - core noise, at least on an OASPL basis (Fig. 15, left). But fan noise again rises to prominence on a PNLT basis when discrete interaction tones and spectral content are considered (Fig. 15, right). Fan noise is once again enhanced due to its strong aft-quadrant noise and twin PNLT peaks within the lateral observer area of integration. Jet noise and core noise, owing to their lowfrequency, broadband content, are favored by the PNLT metric. Even so, the levels of lateral core noise are notable, rivaling even fan noise. Somewhat worrisome - as discussed earlier - is the core noise prediction method's inability to predict core noise at overall pressure ratios in excess of 30. The overall pressure ratio at lateral power and 180 ktas is approximately 34 , resulting in perhaps an under prediction of lateral core noise by an unknown amount. The contribution of jet noise to the lateral EPNL is very small. If the core nozzle chevrons are analytically removed, lateral noise is predicted to increase by only $0.1 \mathrm{EPNdB}$. This suggests that - for this design - the core nozzle chevrons may be omitted if their thrust performance penalty is unacceptable. The contributions of the airframe noise sources to the lateral EPNL are negligible. Flap and trailing edge noise are nonzero, but make no significant contribution to the lateral EPNL. Gear are retracted after use, and the slat gaps are effectively sealed on their departure setting, resulting in no contribution to lateral noise at all. The overall lateral EPNL is 81.5 EPNdB.

The flyover observer has significant PNLT contributions of aft fan, core, and even airframe trailing edge noise (Fig. 16, right, and Fig. 17). The throttle cutback effectively eliminates jet noise altogether. The overall pressure ratio at the noise abatement cutback throttle setting is less than the core noise model maximum, so core flyover noise may reasonably be expected to be accurate, according to early results from the acoustic tool benchmarking study 
(Ref. 16). That core noise contributes at all is a source of concern, however, as is the unexpectedly high level of airframe trailing edge noise. The overall flyover EPNL is 81.6 EPNdB.

The margins relative to the Stage 3 and 4 noise rule stringency limits are computed based on an airplane having a maximum takeoff gross weight of 159,200 lb (See Ref. 5.). The approach, lateral, and flyover EPNLs computed for the N+1 airplane are plotted in Fig. 18, Fig. 19, and Fig. 20, respectively. Also plotted in the figures are the

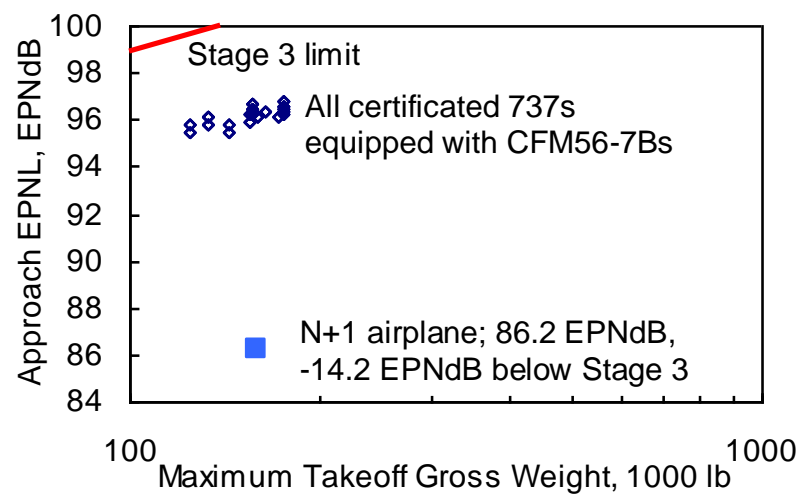

Figure 18. Approach certification noise

published EPNLs of all currently-certificated nextgeneration 737s equipped with CFM56-7B series turbofans, as well as the maximum takeoff gross weightdependent Stage 3 noise limits (defined in Ref. 1 and denoted by red lines).

The FAA's new Stage 4 noise regulations are based on the Chapter 4 noise standard approved by ICAO in 2001 in Annex 16 of their International Standards and Recommended Practices. The Stage 4 noise standard applies to any new subsonic aircraft type application submitted after January 1, 2006, for countries that use Annex 16 as its noise certification basis. Loosely stated, the FAA interprets Stage 4 limits to be: 1) the airplane may not exceed the Stage 3 limits at any of the three measurement points (Stage 3 rules allowed small trades); 2) the cumulative margin relative to the Stage 3 limits must be 10 EPNdB or greater; and 3) the sum of any two of the Stage 3 margins must be 2 EPNdB or greater.

The N+1 airplane's computed margins relative to the Stage 3 limits for the approach, lateral, and flyover observers are -14.2 EPNdB, -15.2 EPNdB, and -9.7 EPNdB, respectively. The predicted cumulative margin relative to Stage 3 is -39.1 EPNdB; making the cumulative Stage 4 margin -29.1 EPNdB. The N+1 airplane has considerable margin at the approach and lateral locations, especially when compared to the next-generation $737 \mathrm{~s}$ currently in service. The margin at the flyover location, however, is less, and even lies within the lower range of the $737 \mathrm{~s}$. This is attributed to the behavior of the Advanced Ducted Propulsor Fan 1: its overall noise does not drop significantly when rotational speed is reduced from maximum to the cutback condition. In the future, improved design practices for UHB fans may more greatly reduce fan noise at cutback power and improve the flyover margin.

\section{Conclusions}

An in-depth, self-consistent, systems analysis study of an engine and airplane system using accepted NASA tools and methods is presented. Progress is measured toward the NASA Subsonic Fixed Wing Project's N +1 noise goal of -32 cumulative EPNdB relative to Stage 4 limits. This analysis places the notional N+1 airplane's Stage 4 cumulative margin at $-29 \mathrm{EPNdB}$; or $3 \mathrm{EPNdB}$ short of the earlier 2005 study that established the goal. To add perspective, the Stage 4 cumulative margins of current, next-generation 737-600, -700, -800, and -900 models range between $-1 \mathrm{EPNdB}$ to $-8 \mathrm{EPNdB}$, making the $\mathrm{N}+1$ airplane considerably quieter than its predecessors in that vehicle class. As another point of reference, the new PurePower PW1000G 17,000 lb-23,000 lb thrust class geared turbofan, slated for the CSeries twinjet, is currently projected by Pratt \& Whitney to have a cumulative Stage 4 margin of -20 $\mathrm{EPNdB} .{ }^{36}$ 
The 3 EPNdB discrepancy between the -29 EPNdB margin calculated in this assessment and the earlier 2005 study that established the -32 EPNdB goal may be explained by any or all of the following: 1) the incorporation of new thrust lapse, trajectory, and throttle modeling; 2) the unexpectedly high level of fan noise at the flyover condition; and 3) the use of improved analytical tools, methods, and assumptions. Despite this new result, the -32 EPNdB N+1 noise reduction goal remains the same. This 3 EPNdB shortfall indicates that a slightly greater reliance on noise reduction technologies will be needed to achieve the goal. Some technologies under consideration that may be used to close the gap may include scarfed inlets, low-count stator technologies, and advanced acoustic liners, such as 3-degree of freedom, zero-splice, or nose lip liners.

As shown by this study, as the once-historically dominant noise sources such as jet noise and fan noise are pushed lower by way of ultrahigh bypass ratio engine cycle design and innovative noise reduction technologies, other noise sources become important and require attention. For example, airframe trailing edge noise is seen here to perhaps now be a contributor to flyover noise. And engine core noise, in this case exacerbated by an engine design incorporating a high overall pressure ratio, contributes to lateral and flyover noise. A need is foreseen for improved engine core noise modeling methods at NASA that reflect the high overall pressure ratios of modern engines.

Lastly, this airplane represents the "low-noise corner" of the design trade space, and it may not be characteristic of a balanced, profitable, business-case airplane design. In the interest of noise reduction, it has an engine cycle design that would not result in minimum block fuel, takeoff gross weight, or cost. This design also uses highly advanced engine and airframe noise reduction technologies to come within reach of NASA's aggressive goal. An actual 737 replacement aircraft may not be as quiet as the $\mathrm{N}+1$ vehicle studied here. However, this study does indicate that if an aggressive, noise-focused design is pursued, it is possible to come within reach of the noise goal.

\section{References}

${ }^{1}$ Code of Federal Regulations, Title 14, Chapter I, Part 36. Noise standards: Aircraft type and airworthiness certification.

${ }^{2}$ Berton, J.J., Bridges, J.E., Burley, C.B., Envia, E., Jones, M.G., and Khorrami, M.R.: "Subsonic Fixed Wing N+1 Noise Goal Study," Acoustics Technical Working Group Meeting, Williamsburg, VA, September 23-24, 2008.

${ }^{3}$ Envia, E., Berton, J.J., Bridges, J.E., Burley, C.B., Jones, M.G., Khorrami, M.R., and Rawls, J.R.: "Progress Toward SFW N+1 Noise Goal," 2nd Annual Fundamental Aeronautics Program Meeting, Atlanta, GA, October 7-9, 2008.

${ }^{4}$ Envia, E., Berton, J.J., Bridges, J.E., Burley, C.B., Jones, M.G., Khorrami, M.R., and Rawls, J.R.: "N+1 Generation: Noise and Fuel Burn Reduction," Fundamental Aeronautics Program, Subsonic Fixed Wing Project, 12-Month Program Review, Washington, D.C., November 5-6, 2008.

${ }^{5}$ Guynn, M.D., Berton, J.J., Fisher, K.L., and Thurman, D.R.: "Engine Concept Study for an Advanced Single-Aisle Transport," Submitted for publication; NASA TP to be published, 2009.

${ }^{6}$ Perra, M.; and German, N.: "Pratt \& Whitney Launches PurePower Engine Family," United Technologies Corp., Pratt \& Whitney press release, 14 July 2008.

${ }^{7}$ Norris, G.; and Wall, R.: "Boeing Goes Back to Drawing Board for 737 Follow-on," Aviation Week and Space Technology, 18 May, 2008.

${ }^{8}$ Lytle, J.K.: "The Numerical Propulsion System Simulation: An Overview,” NASA TM-2000-209915.

${ }^{9}$ NPSS User Guide Software Release: NPSS_1.6.4.

${ }^{10}$ Onat, E., and Klees, G.: "A Method to Estimate Weight and Dimensions of Large and Small Gas Turbine Engines," NASA CR 159481, 1979.

${ }^{11}$ McCullers, L.A.: "Aircraft Configuration Optimization Including Optimized Flight Profiles," Proceedings of the Symposium on Recent Experiences in Multidisciplinary Analysis and Optimization, NASA CP 2327, April 1984.

${ }^{12}$ Code of Federal Regulations, Title 14, Chapter I, Part 25. Airworthiness Standards: Transport Category Airplanes.

${ }^{13} 737$ Airplane Characteristics for Airport Planning, D6-58325-6, Boeing Commercial Airplanes, October 2005, URL: http://www.boeing.com/commercial/airports/737.htm [cited 2/23/2009].

${ }^{14} 787$ Dreamliner Program Fact Sheet, URL: http://www.boeing.com/commercial/787family/programfacts.html [cited 2/23/2009].

${ }^{15}$ Gloudemans, J.R.; Davis, P.C.; and Gelhausen, P.A.: “A Rapid Geometry Modeler for Conceptual Aircraft,” AIAA-19960052, January, 1996.

${ }^{16}$ Dahl, Milo D.: “A Process for Assessing NASA's Capability in Aircraft Noise Prediction Technology,” AIAA Paper 20082813, NASA TM-2008-215268, 2008.

${ }^{17}$ Burley, C.L.; Rawls, J.W., Jr.; Berton, J.J.; and Marcolini, M.A.: "Aircraft System Noise Prediction," NASA report to be published, 2009.

${ }^{18}$ Gillian, R.E.: “Aircraft Noise Prediction Program User's Manual,” NASA TM-84486, 1983.

${ }^{19}$ Zorumski, W.E.: “Aircraft Noise Prediction Program Theoretical Manual,” NASA TM-83199, 1981, Parts 1 and 2 (Currently maintained at NASA LaRC by the ANOPP team in electronic format and provided upon request; Latest revision: January 2009). 
${ }^{20}$ Stone, J.R., Krejsa, E.A., Clark, B.J., and Berton, J.J.: "Jet Noise Modeling for Suppressed and Unsuppressed Aircraft in Simulated Flight," NASA TM-2009-215524, 2009.

${ }^{21}$ Hunter, C.A.; Bridges, J.E.; Khavaran, A.: “Assessment of Current Jet Noise Prediction Capabilities,” AIAA Paper 20082933; NASA TM-2008-215275, 2008.

${ }^{22}$ Janardan, B.A.; Hoff, G.E.; Barter, J.W.; Martens, S.; Gliebe, P.R.; Mengle, V.; and Dalton, W.N.: “AST Critical Propulsion and Noise Reduction Technologies for Future Commercial Subsonic Engines - Separate-Flow Exhaust System Noise Reduction Evaluation," Final Report: NAS3-27720, Area of Interest 14.3, General Electric Report R98AEB152, May 1998.

${ }^{23}$ Dittmar, J.H.; Elliott, D.M.; and Bock, L.A.: "Some Acoustic Results from the Pratt and Whitney Advanced Ducted Propulsor - Fan 1,” NASA TM-1999-209049, 1999.

${ }^{24}$ Kontos, K.B.; Janardan, B.; and Gliebe, P.R.: "Improved NASA-ANOPP Noise Prediction Computer Code for Advanced Subsonic Propulsion Systems Volume 1: ANOPP Evaluation and Fan Noise Model Improvement," NASA CR-195480, 1996.

${ }^{25}$ Envia, E.; Woodward, R.P.; Elliott, D.M.; Fite, E.B.; Hughes, C.E.; Podboy, G.G.; Sutliff, D.L.: "An Assessment of Current Fan Noise Prediction Capability,”NASA TM-2008-215415, 2008.

${ }^{26}$ Kontos, K.B.; Kraft, R.E.; and Gliebe, P.R.: "Improved NASA-ANOPP Noise Prediction Computer Code for Advanced Subsonic Propulsion Systems. Volume 2: Fan Suppression Model Development,” NASA CR-202309, 1996.

${ }^{27}$ Neubert, R.; Bock, L.; Malmborg, E.; and Owen-Peer, W.: “Advanced Low Noise Research Fan Stage Design,” NASA CR 97-206308, 1997.

${ }^{28}$ Jones, M.; Parrott, T.; Sutliff, D.; Hughes, C.: "Assessment of Soft Vane and Metal Foam Engine Noise Reduction Concepts," 15th AIAA/CEAS Aeroacoustics Conference, AIAA-2009-3142, 2009.

${ }^{29}$ Sutliff, D.; Jones, M.; and Hartley, T.: "Collaboration with Williams International to Demonstrate the Characteristics of a Foam-Metal-Liner Installed Over-the-Rotor of a Turbofan Engine," Acoustics Technical Working Group Meeting, 23-24 Sep. 2008, Williamsburg, VA, United States.

${ }^{30}$ Emmerling, J.J.; Kazin, S.B.; and Matta, R.K.: "Core Engine Noise Control Program. Volume III, Supplement 1 Prediction Methods," FAA-RD-74-125, III-I, Mar. 1976 (Available from DTIC as AD A030 376. )

${ }^{31}$ Ho, P.Y.; and Doyle, V.L.: "Combustion noise prediction update," $5^{\text {th }}$ AIAA Aeroacoustics Conference, Seattle, WA, AIAA Paper 1979-0588, 1979.

${ }^{32}$ Weir, D.S., editor: "Engine Validation of Noise and Emission Reduction Technology, Phase I," Honeywell Report No. 21 13843, Honeywell Aerospace, Phoenix, AZ; also NASA CR-2008-215225, 2008.

${ }^{33}$ Fink, M.R.: “Airframe Noise Prediction Method," FAA-RD-77-29, March, 1977.

${ }^{34}$ Humphries, W.M.; Burley, C.L.; and Brooks, T.F.: "Scale-Model Landing Gear Noise Spectra and Directivity," Acoustics Technical Working Group Meeting, 23-24 Sep. 2008, Williamsburg, VA, United States.

${ }^{35}$ Streett, C.L.; Casper, J.H.; Lockard, D.P.; Khorrami, M.R.; Stoker, R.W.; Elkoby, R.; Wenneman, W.F.; and Underbrink, J.R., "Aerodynamic Noise Reduction for High-Lift Devices on a swept Wing Model," $44^{\text {th }}$ AIAA Aerospace Sciences Meeting and Exhibit, Reno, NV, AIAA Paper 2006-212, 2006.

36،Pratt \& Whitney PurePower PW1000G Engines: This Changes Everything," Pratt \& Whitney fact sheet, 2008, URL: http://www.pw.utc.com/StaticFiles/Pratt\%20\&\%20Whitney\%20New/Media\%20Center/Assets/1\%20Static\%20Files/Docs/comm ercial_purepower_july08.pdf [cited 3/19/2009]

15 of 15

American Institute of Aeronautics and Astronautics 